\title{
THE INCLUSION OF NATURAL ELEMENTS IN BUILDING DESIGN: THE ROLE OF GREEN RATING SYSTEMS
}

\author{
I. OBERTI \& F. PLANTAMURA \\ Politecnico di Milano, Department of Architecture, Built Environment and Construction Engineering.
}

\begin{abstract}
The awareness of the heavy impact that the building sector exerts on the natural environment is now widely shared, leading to a wide spread of tools (rules, regulations, voluntary rating) to control and guide towards building environmental sustainability. In this shared vision, the natural environment is perceived essentially as an asset to protect. But nature is not just something to be protected, it is also a key factor to improve the quality of our built environment and our well-being. Numerous studies analyze the positive impact of the introduction of natural elements in building design (i.e. green walls, indoor green, aquatic elements, etc.), including: reduced energy consumption, improved IAQ, benefits on users' attention capacity in office settings, stress-reducing effects in healthcare environments. However, despite this evidence, the use of natural elements in common building practice is still not quite widespread. There is therefore a need to promote awareness and use of the potential of the natural elements in design. This paper aims to assess and promote the enhancement of the natural elements in the voluntary green rating systems, as active tools in promoting environmental sustainability to all the actors of the building process. To this end, the study was developed through the following steps: 1 . in the literature, identification of the elements of nature-based design with more evidence on environmental performance; 2. in green rating systems, identification of the weight given to the natural elements, evaluation of their current level of enhancement within the systems and identification of possible areas of development.
\end{abstract}

Keywords: benefits, green systems, LEED, plants.

\section{INTRODUCTION}

The awareness of the heavy impact that the building sector exerts on the natural environment is now widely shared, leading to a wide spread of tools (rules, regulations, voluntary rating systems) to control and guide towards building environmental sustainability. In this shared vision, the natural environment is perceived essentially as an asset to protect.

But nature is not just something to be protected, it is also a key factor to improve the quality of our built environment. Recognizing this role, some experts advocate a "reinvented relationship" between architecture and nature [1].

The importance of human contact with nature is recognized. Since ancient times and across the globe, plants and gardens have been considered needful for physical and mental wellbeing.

Since the last century, some research has been undertaken to understand the mechanisms underlying this positive impact. For example, these have explored the human positive response towards some natural environments, particularly the savanna habitat, as a result of our evolutionary origins and suitability of this habitat for human survival [2, 3]. 
At the same time, numerous studies have been initiated to find evidence on the benefits obtainable from the introduction of natural elements in the design. To date, the scientific information is very wide and shows, in addition to specific studies, thematic reviews on areas of benefits both environmental, such as reduction of impact in terms of energy consumption [4], and social in terms of physical and psychological well-being [5, 6].

The awareness of environmental and wellbeing benefits, combined with the effect of aesthetic awareness and attractiveness of the green in the design, has led to the construction of buildings in which the natural elements play a fundamental role. The examples, however, are generally delimited to prestigious buildings. The use of natural elements in common building practice is still not quite widespread. On the base of the recognized benefits, some researchers have developed criteria to guide the designer towards the introduction of the green in the design. An example is related to the criteria for a "Biophilic design" developed by prof. Kellert [7]. However, there is a need to promote wider dissemination of awareness and use of the natural elements in the design.

At the moment, one of the means can support this diffusion is referred to the voluntary rating systems, active tools in promoting environmental sustainability to all the actors of the building process, from investors to the end user.

Nowadays, these tools are focused on low-impact design but the road to improved profitability of green elements is open. The same US Green Building Council offers articles and guides that promote biophilic design [8].

In this context, this paper aims to assess how the inclusion of natural elements in design is supported by voluntary green rating systems. Moreover, it looks for new possible areas for requirements related to the inclusion of green in project, in order to promote the enhancement of natural elements in design practice.

\section{METHOD}

The study was developed through the following two steps:

\subsection{Identification of effective natural elements}

In the literature, the environmental benefits have been identified referring to the inclusion of natural elements in building design.

For the purposes of this study, the natural elements in the design were divided into categories depending on the location in the building, the presence or absence of contact with the occupants of the building, the participation or not in the technological system.

For the various green elements, the positive effects were analyzed. The multiple benefits identified were divided into impact areas: Sustainable Site, Energy saving, Comfort \& IAQ, Wellbeing.

The analysis of the obtained information (quantity and quality of evidences) has allowed to identify the most effective elements regarding different environmental issues and uses.

\subsection{Evaluation and enhancement of greenery in green rating systems}

In green rating systems, identification of the weight given to the natural elements as a response to the requirements of environmental improvement.

We have held appropriate to focus our analysis on the LEED rating system, considered its wide diffusion globally, as the figures show. The use of LEED outside the United States 
continues to grow rapidly: as of January 2016, approximately 43 percent of all square footage pursuing LEED certification existed outside the U.S. [9].

By comparing the LEED credit analysis and the result of the first step, it should be possible to identify the credits in which include references to the greenery solutions.

\section{RESULTS}

\subsection{Effective natural elements}

\subsubsection{Greening systems}

In literature, the benefits referred to the introduction of the green in the building design are amply documented and they are referred to different typologies of greenery systems (from the single plant in a vase to whole gardens).

In this study, it has been considered the different green elements, classifying according to the:

- location in the building: Indoor, Envelope, Outdoor;

- contact with the user: Absent/Present.

Another distinction has been carried out according to the type of the technological support for the greenery systems, that is among simple green elements (in vase or in the soil) and green technological systems.

Green technological systems shall be understood as:

- Green walls (or Living walls), external or internal to the building, self-sufficient systems (hydroponic green walls, green wall boxes), in which the plants receive water and nutrients mainly from within the technological support (by drip irrigation system and fertilizer injector) instead from the ground [10]. These systems differ from green facades e green shields, simply based on the use of climbing plants without the technological complexity of the living wall systems.

- Green roofs, modular or monolithic, an engineered setup of different high performance layers that allow the growth of vegetation on rooftop in a thinner and lighter profile then in the soil one. They can need more or less irrigation and maintenance depending on their more or less intensive type [11].

\subsubsection{Greening systems and benefits}

Following we report the benefits associated with the various green elements taken into consideration. Although all elements analyzed have some positive impact, in the literature it was possible to identify those with more evidences (amount of scientific studies and importance of identified impacts).

The benefits, related to the building and its occupants, have been classified into four areas of impact:

- Sustainable Site: Habitat, Rainwater management, Reduction of heat island

- Energy saving: Heating, Cooling

- Comfort \& IAQ: Thermohygrometric, Visual, Acoustic, Indoor pollution reduction

- Wellbeing: Stress reduction, Attention, Care Outcomes. 
3.1.2.1 Sustainable Site Modern cities are a conglomerate of built environments with high density of hard surface. This habitat is very far from the natural one, and it leads to a series of environmental issues at site scale. A significant component of green outdoor in the building design can contribute to rebalance the environmental conditions and to protect the habitat of the site [12].

One of the urbanization effects on local site is an increase of the area of impermeable surfaces. In turn, this has consequences on rainwater management.

A higher proportion of green areas, including the green roof, helps to restore a flow of rainwater similar to the natural one, lowering and delaying the peak runoff [13].

Another negative effect of the replacement of the natural landscape with hard, non-porous, dark surfaces is the effect on the local microclimate: urban microclimates tend to be significantly warmer in comparison with the climates of the surrounding rural areas. This phenomenon, recognized as the urban heat island effect, can be mitigated by green areas on land, green roof and green in façade [14].

3.1.2.2 Energy saving The green wall and the shielding trees produce great benefits related to the thermal aspects (thermal comfort, reducing air conditioning consumption). The best results are obtained in summer climatic condition.

Regarding the shading elements, if these are outside the windows, the cooling effect is greater because the solar radiation is intercepted before it penetrates inside [15]. This effect can be determined both from green wall (green shield outside the windows, such as green screen or green balcony and roof garden with shadowing elements) and green outdoor (shielding trees). An important cooling effect is determined by green walls and green roofs, through natural shading of the building envelope and cooling due to evapotranspiration. Moreover, particularly in the green roof, the growing medium and its water content increase the thermal inertia of building envelope [16].

So, the greening technological systems (green walls and green roofs), if carefully designed and maintained, can be considered as effective systems for energy savings.

Also in winter months, green vegetation could reduce the heat transfer through the building facade. Moreover, green vegetation systems act also as a wind barrier and consequently block the effect of cold wind on building façade. However, some studies demonstrated that the green vegetation is not cost-effective in winter months or cold climatic regions due to the low energy savings performance [17].

3.1.2.3 Comfort \& IAQ Regarding the indoor plants, some positive effects are found in terms of comfort and, partly, of energy consumptions reduction.

The indoor plants add moisture to the air through transpiration from their surface and evaporation from growing media and drainage dish surface. In this way, they contribute in maintaining the relative humidity in a comfort range [18].

The intake of moisture also contributes to summer cooling environments thereby reducing the consumptions for the indoor cooling [19].

Moreover, indoor plants placed near the windows provide seasonal variable shading, reducing the thermal discomfort due to direct radiation, and improve visual comfort through the glare control.

Regarding the noise comfort, indoor green elements (shields, living wall, panels) can act as passive acoustic insulation system, absorbing sound in a noisy places and isolating adjacent 
environments [20]. Their presence can still act positively on the perceived noise level, creating a more acceptable environment [21].

Greater evidence are related to the positive effects of the indoor plants on IAQ. Knowles et al. [22] demonstrated that more than $80 \%$ of indoor pollutants such as TVOCs can be removed through the use of indoor vegetation. Su and Lin [19] performed a field experiment and found that the density of $\mathrm{CO}_{2}$ was reduced from 2,000 to $600 \mathrm{ppm}$ in 5.37 hours. In a UK study of homes with flueless gas appliances, houses with six or more potted-plants showed reductions of over one third in $\mathrm{NO}_{2}$ levels [23].

3.1.2.4 Wellbeing A high positive impact in terms of reducing levels of stress and increase of restorativeness is shown in reference to the interaction between green and humans [24, 25]. To this end, it is not decisive whether the green is indoor or outdoor, but if there is a contact with the occupants. This contact can be active, in the case of usable spaces, or passive, for example, if it is created by the view of indoor plants, the view of the green from a window [26], or even only the view of some green element representations [27].

Stress reduction and resilience increase produce other positive effects such as increase of attention, creativity, psychological and physical resilience. Some studies examine these benefits in specific indoor environment such as the workplaces, where it is found an improvement of the human performance.

A reduction in stress increases the coping abilities of the individual (ability to address, manage, bear a particular problematic situation), thereby improving the attention and productivity. Experiments in office setting demonstrate that common interior plants act simultaneously on stress reduction, restoration of attention capacity and productivity [18, 28]. Positive results have also been seen in school settings [29]. Moreover, the wellbeing due to plants indoor affects has positive consequences in terms of absences reduction both among students and workers [30,31].

Another important indoor environment is represented from the healthcare settings, where the beneficial effects of green are on the general wellbeing of patients, family members and care staff and on the results of the care process and on staff performances. Since the article "View through a window may influence recovery from surgery", by Ulrich [24], studies and evidence about the benefits of green in healthcare settings have greatly increased [32]. So, by now, access to the nature is one of the main recommendations of evidence-based healthcare design [33]. A part in this research area is dedicated to the healing garden, designed as a retreat and a place of respite for patients, visitors, and staff [34]. They can include specific types such as therapeutic and horticultural therapy ones [35].

The Table 1 shows a schematization of green elements and their benefits, with a concise classification of efficacy based on available scientific evidence.

\subsection{Green element enhancement in green rating systems}

We have identified credits/requisites related to the green elements in the rating system LEED.

To date in the USGBC's LEED system, there is a lack of formal credits for the inclusion of plant programs. Few references related to the green elements are present in the following credits:

- Sustainable Site

- Site Development - Protect or restore habitat - To preserve and protect $40 \%$ of the greenfield area on the site, also using native or adapted vegetation. Projects may include 
Table 1: Effective natural elements.
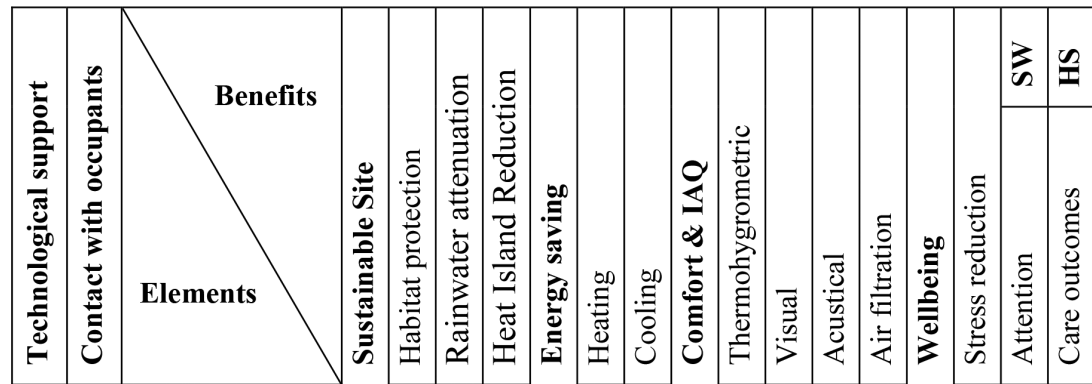

INDOOR

\begin{tabular}{|c|c|l|}
\hline$\square$ & $\sqrt{ }$ & Potted plants \\
\hline$\approx$ & $\sqrt{ }$ & Green panels \\
\hline$\square$ & $\sqrt{ }$ & Green shields \\
\hline$\square$ & $\sqrt{ }$ & Gardens \\
\hline
\end{tabular}
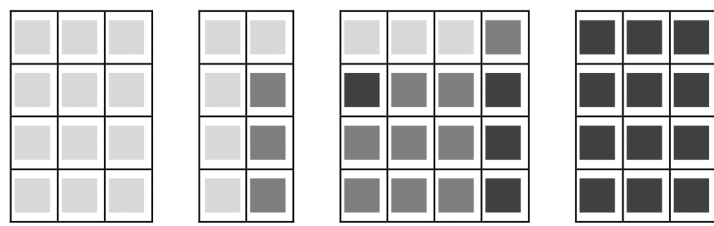

ENVELOPE

\begin{tabular}{|l|l|l|}
\hline$民$ & $\bigotimes$ & Green walls \\
\hline$\sum$ & $\bigotimes$ & Green roofs \\
\hline$\square$ & $\sqrt{ }$ & Green shields \\
\hline$\square$ & $\sqrt{ }$ & Green area \\
\hline
\end{tabular}
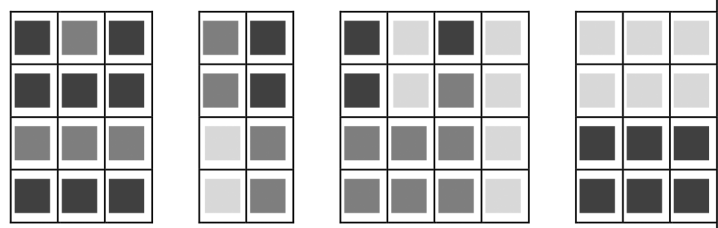

OUTDOOR

\begin{tabular}{|l|l|l|l|l|l|l|}
\hline$\square$ & $\sqrt{ }$ & Shielding trees \\
\cline { 1 - 2 } & $\sqrt{ }$ & & & & \\
\hline$\square$ & $\sqrt{ }$ & View on green & & & \\
\hline$\square$ & $\sqrt{ }$ & Gardens & & & & \\
\hline
\end{tabular}
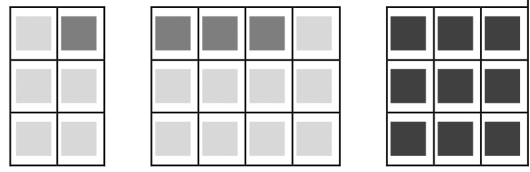

\section{Legenda}

\begin{tabular}{|c|c|c|c|c|c|}
\hline Efficacy: & & Low & & Medium & \multirow{3}{*}{$\begin{array}{l}\text { Spaces use: } \\
\text { HS - Healthcare Settings } \\
\text { SW - School \& Workplace }\end{array}$} \\
\hline Support: & $\square$ & Soil & 芦 & Technological system & \\
\hline Contact: & $\otimes$ & Absent & $\sqrt{ }$ & Present & \\
\hline
\end{tabular}

vegetated roof surfaces if the plants are native or adapted, provide habitat, and promote biodiversity.

- Open space - Outdoor spaces - To provide accessible outdoor space greater than or equal to $30 \%$ of the total site area, of which a minimum of $25 \%$ must be vegetated or have overhead vegetated canopy. Vegetated roof can contribute to credit compliance

- Rainwater management - In a manner best replicating natural site hydrology processes, manage on site the runoff from the developed site using low-impact development (LID) and green infrastructure.

- Heat Island Reduction - To minimize effects on microclimates and human and wildlife habitats by reducing heat islands, using a combination of strategies that also include plants for providing shade for non-roof areas and vegetated roofs.

- Indoor Environmental Quality 
- Quality views - To give building occupants a connection with the natural outdoor environment by providing quality views, including at flora, fauna, or sky view.

Moreover, in the LEED for Healthcare, there are references on the green in these credits:

- Prerequisite

- Integrative project planning and Design - To emphasize human health as a fundamental evaluative criterion. One of its requirements is to assemble an integrated project team, including minimum of four professionals among those specified in a list that include Landscape architect.

- Sustainable Site

- Places of respite - To provide outdoor places of respite, accessible to patients and visitors, or indoor ones with direct line of sight to unobstructed views of nature. Among the credit requirements: Horticulture therapy and other specific clinical or special-use gardens unavailable to

- Direct Exterior Access - To provide direct access to the natural environment, such as exterior courtyard, terrace, garden, or balcony.

However, it is possible to achieve points within the LEED section titled "Innovation".

An example is the Wesst Corp Enterprise Center (Albuquerque) that was awarded Silver LEED Certification, in 2009, in part through the use of indoor plants. Key point of the project was an indoor green wall able to filter VOC's (Volatile Organic Compounds), uptake carbon dioxide during photosynthesis, and release fresh oxygen into the atmosphere. The green wall was fully integrated into the buildings air handling system [36].

This kind of green walls, called Biofilter green walls or BioWall, are very good solution in order to receive credits for their innovate indoor quality features.

Other ways that plants can contribute towards LEED credits are to demonstrate issues such as:

- biophilic connection: Despite green spaces in urban areas, accessibility of green project areas for the building users, indoor connection with external natural setting, etc.

- health and well being improvement: lower rate of illness or absenteeism among users, positive users results in building survey, etc.

- energy conservation: rate of energy saved by the introduction of great amount of indoor plants or green systems, etc.

But all this arguments have to be demonstrated on a case by case basis because they have not specific credit's references.

Table 2 summarizes the LEED's credits with references to specific green elements and those credits could include references to inclusion of green.

\section{CONCLUSION}

There is a great amount of evidence about benefits achievable from the inclusion of greenery in buildings, both at site and building scale, and for environmental issues and human health and wellbeing. The green rating systems can be an excellent tool for the green enhancement in the building design, due to their active role in promoting environmental sustainability to all the actors of the building process, from investors to the end user. 
Table 2: LEED for greenery: current and possible references.

\begin{tabular}{llc}
\hline Sustainable site & Site development - protect or restore habitat & $\sqrt{ }$ \\
& Open space - outdoor spaces & $\sqrt{ }$ \\
& Rainwater management & $\sqrt{ }$ \\
Energy \& atmosphere & Heat island reduction & $\sqrt{ }$ \\
Indoor environmental quality & Optimize energy performance & $\mathrm{o}$ \\
& Enhanced indoor air quality strategies & $\mathrm{o}$ \\
& Thermal comfort & $\mathrm{O}$ \\
& Quality views & $\sqrt{ }$ \\
Innovation & Acoustic performance & $\mathrm{O}$ \\
\hline
\end{tabular}

$\begin{array}{llll}\text { Legend } & \sqrt{ } \quad \text { Reference already present } & 0 & \text { Possible reference }\end{array}$

However, actually, in the rating systems the direct references to the green inclusion are few. The LEED, reference system in this work due to its widespread dissemination in USA and around the world, offers few explicit requirements related to the use of green elements, mainly in the category "Sustainable Site". In the category "Innovation" it is possible to achieve points for the inclusion of green. Also in "Energy \& Atmosphere" and "Indoor Environmental Quality" category, it could be possible to propose greenery solutions as alternative to manufactured goods and engineered systems. But, without a formally recognition of the value of greenery, the use of greenery solutions will have to be discussed on a case by case basis.

This work represents a phase towards the recognition of the value of greenery and its enhancement in green rating systems. This enhancement will be a very strong drive to the promotion of the greenery in the building design.

\section{REFERENCES}

[1] Haupt, P., Architecture vs. Nature - a reinvented relationship. WIT Transactions on Ecology on the Built Environment, 142, pp. 37-45, 2014. http://dx.doi.org/10.2495/ARC140041

[2] Balling, J.D. \& Falk, J.H., Development of visual preference for natural environments. Environmental Behavior, 14, pp. 5-28, 1982. http://dx.doi.org/10.1177/0013916582141001

[3] Orians, G.H. \& Heerwagen, J.H., Evolved responses to landscapes. The Adapted Mind: Evolutionary Psychology and the Generation of Culture, eds. J.H. Barkow, L. Cosmides \& J. Tooby, Oxford University: New York, pp. 555-579, 1992.

[4] Raji, B., Tenpierik, M.J. \& Dobbelsteen, A., The impact of greening systems on building energy performance: a literature review. Renewable and Sustainable Energy Reviews, 45, pp. 610-623, 2015. http://dx.doi.org/10.1016/j.rser.2015.02.011

[5] Tarran, J., Torpy, F. \& Burchett, M., Use of living pot-plants to cleanse indoor air research review. Sixth International Conference on Indoor Air Quality, pp. 249-256, 2007.

[6] Lohr, V., Greening the human environment: the untold benefits. Acta Horticulturae, 916, pp. 159-170, 2011. http://dx.doi.org/10.17660/ActaHortic.2011.916.16 
[7] Kellert, R.S., Heerwagen, J. \& Mador, M., Biophilic Design: The Theory, Science and Practice of Bringing Building to Life, John Wiley and Sons: Hoboken, New Jersey, 2008.

[8] Ryan, C., The ROI on biophilic design patterns. 13 Oct 2014. U.S. Green Building Council (USGBC), available at http://www.usgbc.org/articles/roi-biophilic-designpatterns.

[9] U.S. Green Building Council (USGBC), LEED Certification Update: New in 2016, available at http://www.usgbc.org/articles/leed-certification-update-new-2016.

[10] Manso, M. \& Castro-Gomes, J., Green wall systems: a review of their characteristics. Renewable and Sustainable Energy Reviews, 41, pp. 863-871, 2015. http://dx.doi.org/10.1016/j.rser.2014.07.203

[11] International Green Roof Association (IGRA), Green roof types, available at www.igraworld.com/types_of_green_roofs

[12] Lundholm, J., Green roofs and facades: a habitat template approach. Urban Habitats, 4(1), pp. 87-101, 2006.

[13] Berndtsson, J.C., Green roof performance towards management of runoff water quantity and quality: a review. Ecological Engineering, 36, pp. 351-360, 2010.

http://dx.doi.org/10.1016/j.ecoleng.2009.12.014

[14] Price, A., Jones, E.C. \& Jefferson, F., Vertical greenery systems as a strategy in urban heat island mitigation. Water Air Soil Pollution, pp. 226-247, 2015.

http://dx.doi.org/10.1007/s11270-015-2464-9

[15] Hoelscher, M.T., Nehls, T., Britta, J.B. \& Wessolek, G., Quantifying cooling effects of facade greening: shading, transpiration and insulation. Energy and Buildings, 114, pp. 283-290, 2016.

http://dx.doi.org/10.1016/j.enbuild.2015.06.047

[16] Vijayaraghavan, K., Green roofs: a critical review on the role of components, benefits, limitations and trends. Renewable and Sustainable Energy Reviews, 57, pp. 740-752, 2016.

http://dx.doi.org/10.1016/j.rser.2015.12.119

[17] Feng, H. \& Hewage, K., Energy saving performance of green vegetation on LEED certified buildings. Energy and Buildings, 75, pp. 281-289, 2014. http://dx.doi.org/10.1016/j.enbuild.2013.10.039

[18] Lohr, V. \& Pearson-Mims, C.H., Particulate matter accumulation on horizontal surfaces in interiors: influence of foliage plants. Atmospheric Environment, 30, pp. 2565-2568, 1996. http://dx.doi.org/10.1016/1352-2310(95)00465-3

[19] Su, Y.M. \& Lin, C.H., $\mathrm{CO}_{2}$ purify effect on improvement of indoor air quality (iaq) through indoor vertical greening. Proceedings of the World Congress on Engineering 2013, 2, pp. 953-957, 2013.

[20] Azkorra, Z., Pérez, G., Coma, J., Cabeza, L.F., Bures, S., Álvaro, J.E., Erkoreka, A. \& Urrestarazu, M., Evaluation of green walls as a passive acoustic insulation system for buildings. Applied Acoustics, 89, pp. 46-56, 2015. http://dx.doi.org/10.1016/j.apacoust.2014.09.010

[21] Mediastika, C. \& Binarti F., Reducing indoor noise levels using people's perception on greenery. Environmental and Climate Technologies, 11, pp. 19-27, 2013. http://dx.doi.org/10.2478/rtuect-2013-0003 
[22] Knowles, L., MacLean, P., Rosato, M., Stanley, C. \& Volpe, S., Yousif, living wall: a feasibility study for the SLC. University of Waterloo; Final report, ERS 250, 2002.

[23] Coward, M., Ross, D. \& Coward, S., Pilot study to assess the impact of green plants on $\mathrm{NO}_{2}$ levels in homes, building research establishment note N154/96, Watford, UK, 1996.

[24] Ulrich, R.S., Simons, R.F., Losito, B.D., Fiorito, E., Miles, M.A. \& Zelson, M., Stress recovery during exposure to natural and urban environments. Journal of Environmental Psychology, 11(3), pp. 201-230, 1991. http://dx.doi.org/10.1016/S0272-4944(05)80184-7

[25] Kaplan, S., The restorative benefits of nature: toward an integrative framework. Journal of Environmental Psychology, 16, pp. 169-182, 1995. http://dx.doi.org/10.1016/0272-4944(95)90001-2

[26] Ulrich, R.S., View through a window may influence recovery from surgery. Science, pp. 224-420, 1984.

http://dx.doi.org/10.1126/science.6143402

[27] Berto, R., Exposure to restorative environments helps restore attentional capacity. Journal of Environmental Psychology, 25, pp. 249-259, 2005.

http://dx.doi.org/10.1016/j.jenvp.2005.07.001

[28] Raanaas, R.K., Horgen Evensen, K., Rich, D., Gunn Sjøstrøm, G. \& Patilet, G., Benefits of indoor plants on attention capacity in an office setting. Journal of Environmental Psychology, 31(1), pp. 99-105, 2011. http://dx.doi.org/10.1016/j.jenvp.2010.11.005

[29] Daly, J., Burchett, M. \& Torpy, F., Plants in the classroom can improve student performance. National interior plantscape association, 2010.

[30] Fjeld, T., The effect of interior planting on health and discomfort among workers and school children. HorTechnology, 10(1), pp. 46-52, 2000.

[31] Elzeyadi, I., Daylighting-Bias and biophilia: quantifying the impact of daylighting on occupants health, 2011, available at www.usgbc.org/resources

[32] Dijikstra, K., Pieterse, M.E. \& Pruyn, A., Stress-reducing effects of indoor plants in the built healthcare environments; the mediating role of perceived attractiveness. Preventive Medicine, 47, pp. 279-283, 2008. http://dx.doi.org/10.1016/j.ypmed.2008.01.013

[33] Ulrich, R.S., A review of the research literature on evidence-based healthcare design. Health Environments Research and Design, 1(3), pp. 61-125, 2008. http://dx.doi.org/10.1177/193758670800100306

[34] Cooper Marcus, C. \& Barnes, M., Healing Gardens: Therapeutic Benefits and Design Recommendations, John Wiley \& Sons: New York, 1999.

[35] American Horticultural Therapy Association (AHTA), Definitions and positions, 2012, available at http://ahta.org/sites/default/files/DefinitionsandPositions.pdf

[36] Zazzera, J., West corporation gets LEED credit for use of indoor plants, GPGB news, May 3, 2010. 